\title{
Interactions of Desmethoxyyangonin, a Secondary Metabolite from Renealmia alpinia, with Human Monoamine Oxidase-A and Oxidase-B
}

\author{
Narayan D. Chaurasiya, ${ }^{1}$ Francisco León, ${ }^{2}$ Yuanqing Ding, ${ }^{1}$ Isabel Gómez-Betancur, ${ }^{3}$ \\ Dora Benjumea, ${ }^{3}$ Larry A. Walker, ${ }^{1,2}$ Stephen J. Cutler, ${ }^{1,4}$ and Babu L. Tekwani ${ }^{1,2}$ \\ ${ }^{1}$ National Center for Natural Products Research, School of Pharmacy, The University of Mississippi, University, MS 38677, USA \\ ${ }^{2}$ Department of Biomolecular Sciences, School of Pharmacy, The University of Mississippi, University, MS 38677, USA \\ ${ }^{3}$ Programa de Ofidismo/Escorpionismo, Sede de Investigación Universitaria, Facultad de Ciencias Farmacéuticas y Alimentarias, \\ Universidad de Antioquia, Torre 2, Laboratorio 631, Medellín, Colombia \\ ${ }^{4}$ College of Pharmacy, University of South Carolina, Columbia, SC 29208, USA
}

Correspondence should be addressed to Babu L. Tekwani; btekwani@olemiss.edu

Received 23 April 2017; Revised 24 June 2017; Accepted 17 July 2017; Published 24 August 2017

Academic Editor: Cheorl-Ho Kim

Copyright ( 2017 Narayan D. Chaurasiya et al. This is an open access article distributed under the Creative Commons Attribution License, which permits unrestricted use, distribution, and reproduction in any medium, provided the original work is properly cited.

Renealmia alpinia (Zingiberaceae), a medicinal plant of tropical rainforests, is used to treat snakebites and other injuries and also as a febrifuge, analgesic, antiemetic, antiulcer, and anticonvulsant. The dichloromethane extract of $R$. alpinia leaves showed potent inhibition of human monoamine oxidases- (MAOs-) A and B. Phytochemical studies yielded six known compounds, including pinostrobin 1, $4^{\prime}$-methyl ether sakuranetin 2, sakuranetin 3, pinostrobin chalcone 4, yashabushidiol A 5, and desmethoxyyangonin 6. Compound 6 displayed about 30-fold higher affinity for MAO-B than MAO-A, with Ki values of 31 and $922 \mathrm{nM}$, respectively. Kinetic analysis of inhibition and equilibrium-dialysis dissociation assay of the enzyme-inhibitor complex showed reversible binding of desmethoxyyangonin $\mathbf{6}$ with MAO-A and MAO-B. The binding interactions of compound $\mathbf{6}$ in the active site of the MAO-A and MAO-B isoenzymes, investigated through molecular modeling algorithms, confirmed preferential binding of desmethoxyyangonin 6 with MAO-B compared to MAO-A. Selective reversible inhibitors of MAO-B, like desmethoxyyangonin 6, may have important therapeutic significance for the treatment of neurodegenerative disorders, such as Parkinson's disease and Alzheimer's disease.

\section{Introduction}

The Renealmia genus (Zingiberaceae) belongs to the rare class of amphi-Atlantic plants well represented in tropical Africa and Americas [1, 2]. Several Renealmia species have been used for folk medicine and food on both sides of the Atlantic. Decoctions of fruits from $R$. congoensis are used to treat stomachache in Cameroon children [3]. Fruits of $R$. cincinnata are commonly used as a spice and utilized by traditional healers to treat infectious diseases in Northwest Cameroon [4]. In the Americas, several species of Renealmia have been reported to treat different diseases [5]. R. thyrsoidea is used to treat skin infections associated with leishmaniasis and to reduce fever [6]. The crushed stem or infusion of $R$. alpinia is used to treat headaches, stomachaches, and body fatigue by the Amazon-Yanomami Indians [7]. Edible fruits of $R$. alpinia are valuable for taste in the Sierra Norte de Puebla (Mexico) and Ecuador [8]. In Trinidad, R. alpinia crushed fruits mixed with the juice of Costus scaber have been found effective for treatment of snakebites [9]. Otero et al. [10] reported extensive investigations on the native Northwest Colombian medicinal plants used by indigenous EmberaKatios tribes. They highlighted the use of $R$. alpinia rhizomes or/and leaves, as aqueous extracts, decoctions, or poultice for the treatment of snakebites. Moreover, the aqueous extracts of $R$. alpinia showed neutralizing effect against Bothrops asper venom through inhibition of proteinases present in the snake toxin [11]. Pinostrobin, the main bioactive constituent, 
<smiles>COc1cc(O)c2c(c1)O[C@H](c1ccccc1)CC2=O</smiles>

1<smiles>COc1cc(O)c(C(=O)/C=C/c2ccccc2)c(O)c1</smiles>

4<smiles>COc1ccc([C@@H]2CC(=O)c3c(O)cc(OC)cc3O2)cc1</smiles>

2<smiles>O[C@H](CCc1ccccc1)C[C@H](O)CCc1ccccc1</smiles>

5<smiles>COc1cc(O)c2c(c1)O[C@@H](c1ccc(O)cc1)CC2=O</smiles>

3<smiles>COc1cc(/C=C/c2ccccc2)oc(=O)c1</smiles>

6

Figure 1: Chemical structures of Renealmia alpinia constituents. Pinostrobin 1, 4' -methyl ether sakuranetin 2, sakuranetin 3, pinostrobin chalcone 4, yashabushidiol A 5, and desmethoxyyangonin 6.

showed inhibitory effects on the enzymatic, anticoagulant, myotoxic, and edema inducing activities of phospholipase $\mathrm{A}_{2}\left(\mathrm{PLA}_{2}\right)$ isolated from Crotalus durissus venom [12].

Additionally, the extracts of $R$. alpinia showed inhibition towards indirect hemolytic coagulant effects and proteolytic activity produced by $B$. asper venom. Pinostrobin was found to be the bioactive component in the extract responsible for this effect [13]. Recently, we explored the antinociceptive effects of methanol and aqueous extracts of $R$. alpinia in in vivo models. Comprehensive phytochemical analysis of $R$. alpinia yielded pinostrobin 1, along with two flavonoids (naringenin 7,4'-dimethyl ether 2 and naringenin 7-methyl ether 3$)$, one chalcone $\left(2^{\prime}, 6^{\prime}\right.$-dihydroxy- $4^{\prime}$-methoxychalcone 4), one diarylheptanoid (3,5-heptanediol-1,7-diphenyl 5), and one kavalactone (desmethoxyyangonin 6) [14] (Figure 1). This was the first report on the isolation of compound 6 from a Renealmia species [15].

Increasing efforts have been made to identify dual monoamine oxidases (MAOs) inhibitory and anti-inflammatory agents, which enhance cognitive functions and delay/prevent progression of neurodegenerative diseases [1618]. Dichloromethane extract of $R$. alpinia and individual constituents isolated from this extract were evaluated in vitro against the recombinant human MAO-A and MAOB. Binding interactions of desmethoxyyangonin 6, the most prominent MAO inhibitory constituent in R. alpinia extracts, in the active site of the MAO-A and MAO-B isoenzymes were investigated through enzyme-kinetics assays, enzymeinhibitor complex binding, equilibrium-dialysis dissociation analyses, and computational molecular modeling algorithms. These studies may have implications for future research and scientifically validate traditional use of R. alpinia as a potential therapeutic agent for treatment of neurodegenerative disorders as well as the use of R. alpinia as a functional dietary benefit for the local populations.

\section{Materials and Methods}

2.1. Reagents and Chemicals. Pure recombinant human monoamine oxidases (MAO-A and MAO-B) enzymes overexpressed in baculovirus (Autographa californica) infected insect cells (BTI-TN-5B1-4) were purchased from BD Biosciences, (Bedford, MA, USA). Kynuramine bromide, 4hydroxyquinoline, clorgyline, $R(-)$ deprenyl, and DMSO were obtained from Sigma Chemicals Company (St Louis, MO, USA). R. alpinia extract and six evaluated compounds 1-6 were obtained from the isolation procedures described previously [14]. These compounds have been kept at $-20^{\circ} \mathrm{C}$ until evaluation. Previous to assay, to verify the stability of compounds 1-6, the spectrometric and spectroscopic analysis was done. No degradation products were detected.

2.2. Determination of MAOs Inhibition Activity of the Compounds. In vitro assays were performed to measure the inhibitory effects of $R$. alpinia dichloromethane extract and its purified compounds $\mathbf{1 - 6}$ on human recombinant $\mathrm{MAO}-\mathrm{A}$ and MAO-B activity. The dichloromethane extract (0.001 to $100 \mu \mathrm{g} / \mathrm{mL})$, purified compounds $\left(10^{-9}\right.$ to $\left.10^{-2} \mathrm{M}\right)$, and standard MAO inhibitors (phenelzine, clorgyline, and deprenyl) $\left(10^{-12}\right.$ to $\left.10^{-5} \mathrm{M}\right)$ were tested on human MAO$A$ and MAO-B enzymes [19]. Stock solutions of the test compounds/extracts were prepared in DMSO and diluted further in $0.1 \mathrm{M}$ potassium phosphate buffer $(\mathrm{pH} 7.4)$ to obtain the desired concentrations. MAO-A and MAO$B$ activities were determined by fluorometric kynuramine deamination assay set up in 384-well solid white flat-bottom plates [20]. MAO-A and MAO-B inhibition activities $\left(\mathrm{IC}_{50}\right.$ values) were determined using fixed concentration of the substrate kynuramine and varying concentrations of the test compounds or extracts. The enzyme reactions were carried out in $0.1 \mathrm{M}$ potassium phosphate buffer ( $\mathrm{pH}-7.4)$. Reaction mixture (total volume $75 \mu \mathrm{L}$ in each well) contained potassium phosphate buffer (0.1 M, pH 7.4), kynuramine ( $80 \mu \mathrm{M}$ for MAO-A assay and $50 \mu \mathrm{M}$ for MAO-B assay), the 
test compound or extract (to the desired concentration), and the enzyme (375 ng for MAO-A or $937.5 \mathrm{ng}$ for MAO-B). The reaction mixtures with buffer/substrate/inhibitor were preincubated for 10 minutes at $37^{\circ} \mathrm{C}$, followed by addition of MAO-A and MAO-B to initiate the reaction. The solid white microplates were incubated for 20 minutes at $37^{\circ} \mathrm{C}$ and the enzymatic reaction was stopped by addition of $28 \mu \mathrm{L}$ of $2 \mathrm{~N}$ $\mathrm{NaOH}$ to each well. The deaminated product of kynuramine, which spontaneously cyclizes to 4-hydroxyquinoline, was measured fluorometrically at $320 \mathrm{~nm}$ excitation and $380 \mathrm{~nm}$ emission wavelengths with a plate reader (SpectraMax M5, Molecular Devices, Sunnyvale, CA, USA). The $\mathrm{IC}_{50}$ values were computed by XL-Fit ${ }^{\circledR}$ from the dose-response inhibition curves.

\subsection{Enzyme Kinetics and Mechanism of Inhibition of MAOs.}

The potential inhibitor desmethoxyyangonin 6 was selected for inhibition kinetic studies with MAO-A and MAO-B. For the enzyme-kinetics analysis, assays were performed at varying concentrations of kynuramine $(1.90 \mu \mathrm{M}$ to $500 \mu \mathrm{M})$ for determination of the enzyme inhibition constants $(\mathrm{Ki})$ for inhibition of MAO-A and MAO-B with compound 6. In addition to controls without inhibitors, two concentrations (one below and one above $\mathrm{IC}_{50}$ values) of the inhibitors [for MAOA phenelzine $(0.450 \mu \mathrm{M}$ and $0.900 \mu \mathrm{M})$, desmethoxyyangonin $6(0.125 \mu \mathrm{M}$ and $0.250 \mu \mathrm{M})$ and for MAO-B phenelzine $(0.050 \mu \mathrm{M}$ and $0.100 \mu \mathrm{M})$, desmethoxyyangonin $6(0.045 \mu \mathrm{M}$ and $0.090 \mu \mathrm{M})$ ] were tested. Results are presented as double reciprocal Lineweaver-Burk plots. The kinetic data, namely, $K_{\mathrm{M}}, V_{\max }$, and $\mathrm{Ki}$ values, were calculated by SigmaPlot 12.3 with enzyme-kinetics module using Michaelis-Menten equation. The results were also analyzed for the type of inhibition.

\subsection{Equilibrium Dialysis Assay for Analysis of Binding of} Desmethoxyyangonin 6 with MAOs. Binding and inhibition of MAO-A and MAO-B with desmethoxyyangonin 6 were further examined by incubating the enzyme with high concentrations of the inhibitor followed by extensive dialysis of the enzyme-inhibitor complex and recovery of enzyme activities. MAO-A ( $0.05 \mathrm{mg} / \mathrm{mL}$ protein) was incubated with desmethoxyyangonin $6(20 \mu \mathrm{M}$ and $100.0 \mu \mathrm{M})$ and MAO-B $(0.05 \mathrm{mg} / \mathrm{mL}$ protein $)$ was incubated with desmethoxyyangonin $6(1.50 \mu \mathrm{M}$ and $20.0 \mu \mathrm{M})$ in an enzyme incubation mixture of $1 \mathrm{~mL}$ containing $100 \mathrm{mM}$ potassium phosphate buffer ( $\mathrm{pH}$ 7.4). Formation of enzyme-inhibitor complex was allowed by incubation of the reaction mixtures for $20 \mathrm{~min}$ at $37^{\circ} \mathrm{C}$. The enzyme-inhibitor mixtures after incubation were chilled, transferred to the dialysis bags, and dialyzed against $25 \mathrm{mM}$ potassium phosphate buffer ( $\mathrm{pH}$ 7.4) for 14-16 hours at $4^{\circ} \mathrm{C}$ (changing the dialysis buffer three times). The enzyme catalytic activities were measured before and after dialysis.

2.5. Time-Dependent Enzyme Inhibition Assay. MAO-A and MAO-B enzymes were preincubated for different time periods (0-15 min) with the inhibitor. Concentrations of the inhibitor tested for time-dependent inhibition with $20 \mu \mathrm{g} / \mathrm{mL}$ MAO-A were $7.50 \mu \mathrm{M}$ (desmethoxyyangonin 6) and $0.600 \mu \mathrm{M}$ (phenelzine) and with $50 \mu \mathrm{g} / \mathrm{mL}$ MAO-B were $0.40 \mu \mathrm{M}$ (desmethoxyyangonin 6) and $0.100 \mu \mathrm{M}$ (phenelzine). Controls without inhibitors were also run simultaneously. The enzyme activities were determined as described above.

2.6. Computational Methods and Software Packages. The crystal structures of MAO-A and MAO-B were downloaded from the Protein Data Bank with PDB IDs 2Z5X for MAOA [21] and 1OJ9 for MAO-B [22]. Water molecules were removed and protein structures were preprocessed, reviewed, modified, and refined [23], using the Protein Preparation Wizard [24]. A "standard" mode of the ProtAssign algorithm was run to optimize the hydrogen-bonding (H-bond) network at neutral pH. The Impref module of Impact [25] and the OPLS_2005 force field [26-28] were employed to relax the entire structure in the recommended protein preparation protocol. The docking calculations were carried out using the Glide software [29]. The centroid of ligands harmine (HRM) in 2Z5X and 1,4-diphenyl-2-butene (1PB) in 1OJ9 was set as the center of active site. The dock ligand length was set as $25 \AA$ and the XP module in Glide was used to rank the obtained binding poses. Prior to docking, the ligand desmethoxyyangonin $\mathbf{6}$ was prepared using the LigPrep [30]. Molecular mechanics combined with the generalized Born surface area continuum solvation method (MM/GBSA) were employed to calculate the protein-ligand binding free energies of the docking conformations [31], using Prime [32] of the Schrodinger software suite [24]. All residues that have atoms inside $5 \AA$ from the ligand were treated flexibly.

\section{Results}

3.1. MAOs Inhibitory Properties of R. alpinia Extract and Compounds 1-6. R. alpinia dichloromethane extract showed significant inhibitory effect with $\mathrm{IC}_{50}$ values of 3.75 and $1.70 \mu \mathrm{g} / \mathrm{mL}$ for the MAO-A and MAO-B, respectively. The extract was subjected to purification using a silica gel column chromatography, yielding six purified compounds 1-6 (Figure 1). The structures of these constituents were elucidated on the basis of spectroscopic data (EIMS, ${ }^{1} \mathrm{H}$ NMR and ${ }^{13}$ CNMR, HSQC, and HMBC), by comparison with those reported in the literature [14]. Compounds 1-6 were evaluated against MAO-A and MAO-B inhibition assays. Compounds 1-5 showed moderate inhibition effect; however compound 6 exhibited potent MAO inhibition (Table 1). Noticeably, desmethoxyyangonin 6 showed 15-fold more preferential inhibition of MAO-B than MAO-A, evidenced by the $\mathrm{IC}_{50}$ values of 1.850 and $0.123 \mu \mathrm{M}$, for MAO-A and MAO$\mathrm{B}$, respectively (Table 1 , Figure 2 ).

3.2. Enzyme Kinetics and Mechanism of Inhibition of MAO Isoenzymes with Desmethoxyyangonin 6. We further evaluated the kinetics and mechanism of inhibition of human MAO-A and MAO-B isoenzymes by desmethoxyyangonin 6 (Figures 3 and 4). To comprehend the type of inhibition, we examined 6 against both MAO-A and MAO-B at varying concentrations of kynuramine, a nonselective substrate. Desmethoxyyangonin $\mathbf{6}$ was tested at two concentrations: 
TABLE 1: Inhibition ( $\mathrm{IC}_{50}$ values) of recombinant human MAO-A and MAO-B by R. alpinia extract and isolated compounds 1-6.

\begin{tabular}{lccc}
\hline Samples & $\begin{array}{c}\text { Monoamine oxidase-A } \\
\mathrm{IC}_{50}(\mu \mathrm{M})\end{array}$ & $\begin{array}{c}\text { Monoamine oxidase-B } \\
\mathrm{IC}_{50}(\mu \mathrm{M})\end{array}$ & Index MAO-A/B \\
\hline $\begin{array}{l}\text { Renealmia alpinia } \\
\text { dichloromethane extract }\end{array}$ & $3.750 \pm 0.283^{\mathrm{a}}$ & $1.700 \pm 0.2121^{\mathrm{a}}$ & 2.201 \\
Pinostrobin, 1 & $23.895 \pm 1.346$ & $45.547 \pm 4.314$ & 0.524 \\
$4^{\prime}$-Methyl ether & $31.400 \pm 4.577$ & $>100$ & - \\
sakuranetin, 2 & $45.482 \pm 5.715$ & $36.505 \pm 6.626$ & 1.246 \\
Sakuranetin, 3 & $6.326 \pm 0.206$ & $10.036 \pm 3.237$ & 0.610 \\
Pinostrobin chalcone, 4 & $>100$ & $35.384 \pm 0.121$ & - \\
Yashabushidiol A, 5 & $1.850 \pm 0.086$ & $0.1233 \pm 0.0095$ & 15.040 \\
Desmethoxyyangonin, 6 & $0.235 \pm 0.0218$ & $0.150 \pm 0.0095$ & - \\
Phenelzine & $0.0046 \pm 0.003$ & - & - \\
Clorgyline & - & $0.032 \pm 0.012$ & - \\
Deprenyl & - & & \\
\hline
\end{tabular}

${ }^{*}$ The $\mathrm{IC}_{50}$ values computed from the dose response inhibition curves are Mean $\pm \mathrm{SD}$ of triplicate observations. ${ }^{\mathrm{a}} \mu \mathrm{g} / \mathrm{mL}$.
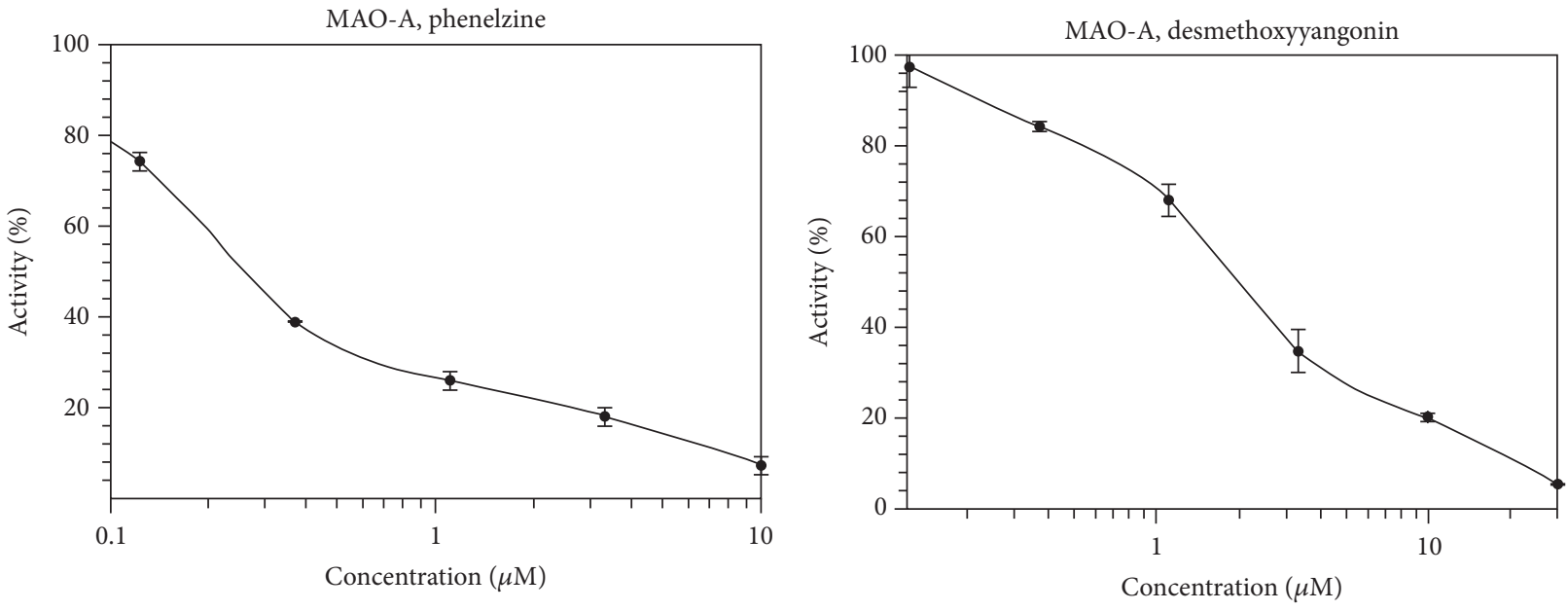

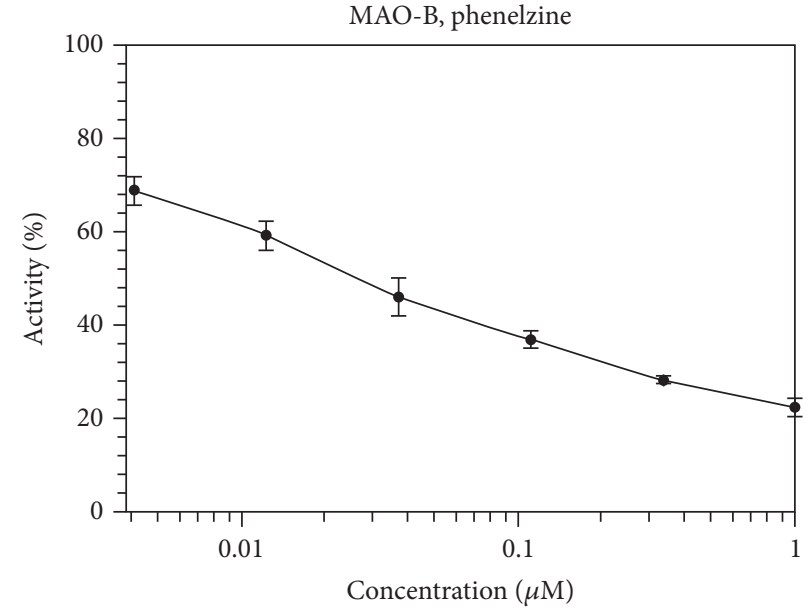

(a)

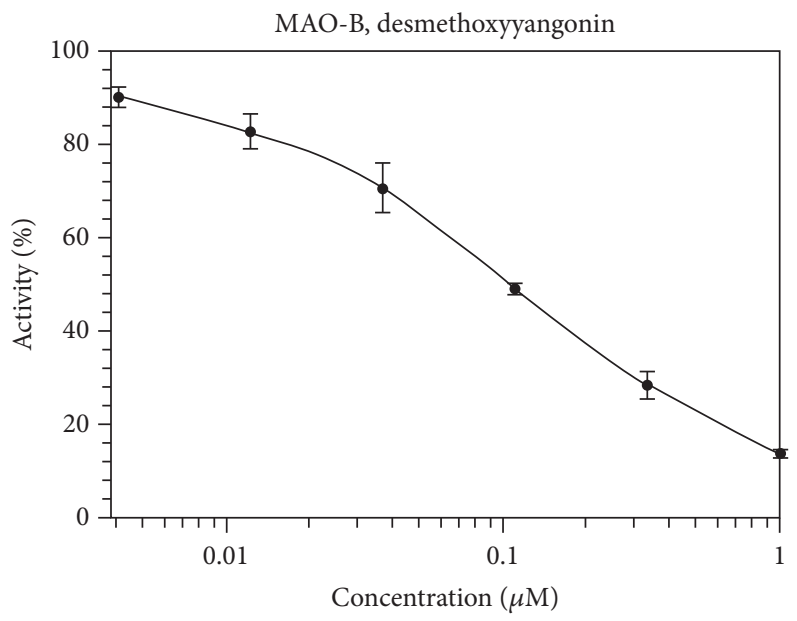

(b)

FIGURE 2: Concentration dependent analysis of inhibition of recombinant human monoamine oxidase-A and monoamine oxidase-B by desmethoxyyangonin 6 and phenelzine. 


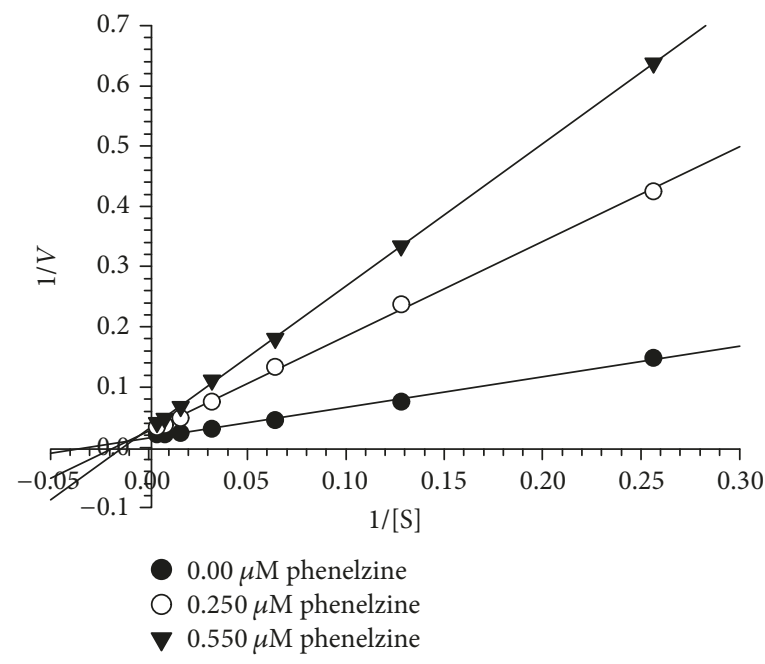

(a)

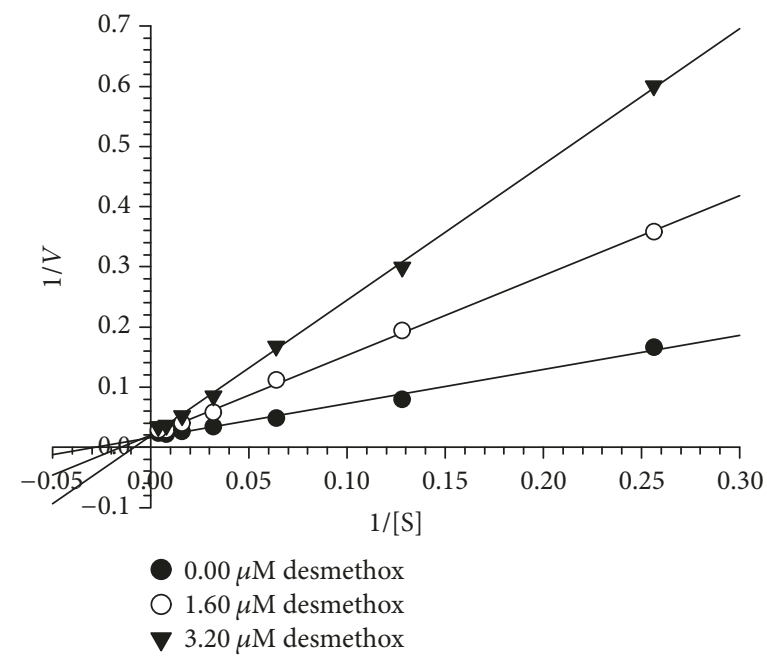

(b)

FIGURE 3: Kinetics analysis of inhibition of recombinant human MAO-A with (a) desmethoxyyangonin 6 and (b) phenelzine; $V=$ $\mathrm{nmoles} / \mathrm{min} / \mathrm{mg}$ protein and $\mathrm{S}=$ substrate (kynuramine) concentration $(\mu \mathrm{M})$.

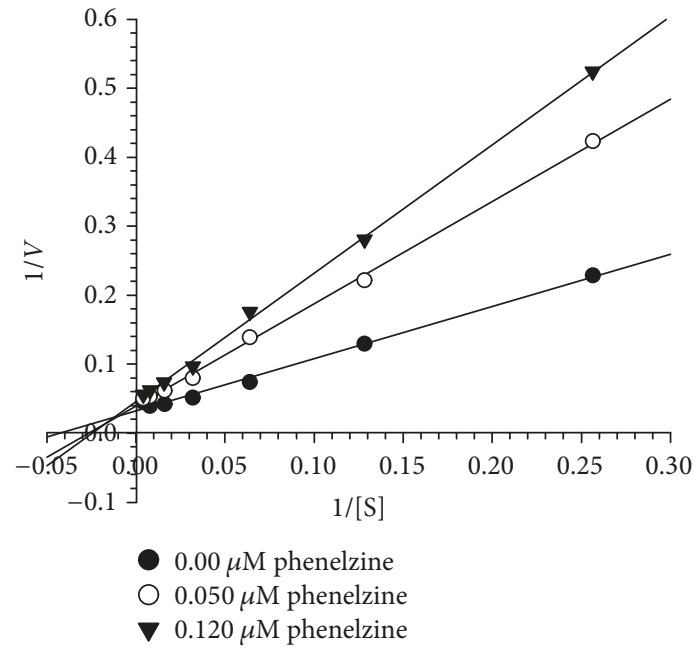

(a)

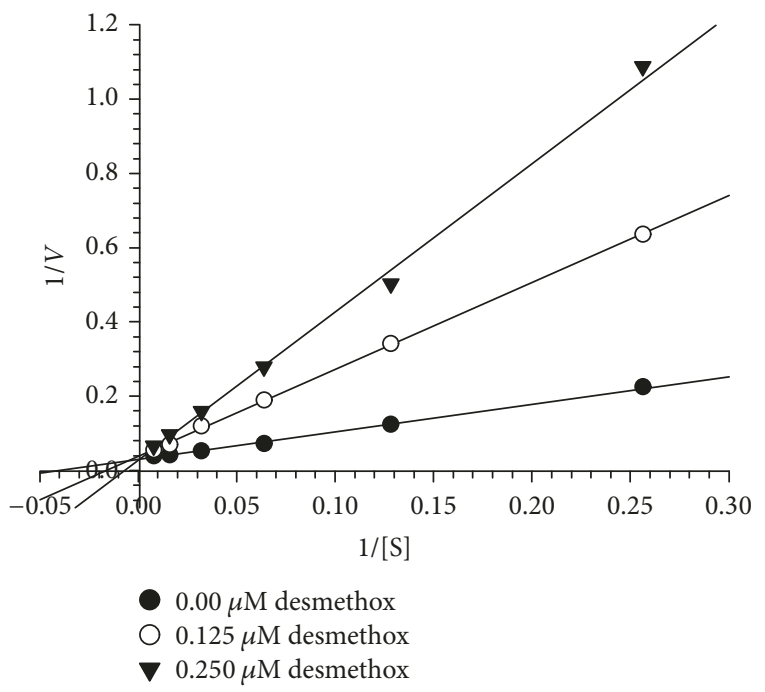

(b)

FIGURE 4: Kinetics analysis of inhibition of recombinant human MAO-B with (a) desmethoxyyangonin 6 and (b) phenelzine; $V=$ nmoles/min/mg protein and $\mathrm{S}=$ substrate (kynuramine) concentration $(\mu \mathrm{M})$.

one above and the other below the $\mathrm{IC}_{50}$ value. For each experiment, three sets of assays were done at variable concentrations of the substrate: two concentrations of the inhibitor/compound and one control without inhibitors. The results are presented as double reciprocal Lineweaver-Burk plots and the kinetic data, namely, $K_{M}, V_{\max }$, and $K i$ values, were computed by SigmaPlot 12.3 with enzyme-kinetics module using Michaelis-Menten equation (Table 2). The results suggest that desmethoxyyangonin 6 binds as a mixed inhibitor with the human MAO-A (Figure 3). However, MAO-B inhibition by 6 was competitive (Figure 4). The binding affinities of compound 6 with MAO-A and MAO-B were compared with reference MAO inhibitors.
3.3. Analysis of Time-Dependent Enzyme Inhibition and Binding of Compound 6 with MAOs. In order to examine the time-dependent binding inhibition of MAO-A and MAO$\mathrm{B}$, the enzymes were preincubated with inhibitor for the indicated time $(0-15 \mathrm{~min})$ at concentrations that caused nearly $60-70 \%$ inhibition (Figure 5). The control enzymes without inhibitor were also run concurrently. The results show that inhibition of MAO-A and MAO-B (Figure 5) by desmethoxyyangonin 6 was not time-dependent. The binding characteristics of desmethoxyyangonin 6 with MAO$\mathrm{A}$ and MAO-B were examined by equilibrium dialysis to measure dissociation of the enzyme-inhibitor complex (Figure 6). MAO-A and MAO-B were incubated with high 
TABLE 2: Inhibition/binding affinity constants $(K i)$ for inhibition of recombinant human MAO-A and MAO-B by desmethoxyyangonin 6 and phenelzine. ${ }^{*}$

\begin{tabular}{lcccc}
\hline \multirow{2}{*}{ Compounds } & \multicolumn{2}{c}{ Monoamine oxidase-A } & \multicolumn{2}{c}{ Monoamine oxidase-B } \\
& $K i(\mathrm{nM})$ & Type of Inhibition & $K i(\mathrm{nM})$ & Type of Inhibition \\
\hline Desmethoxyyangonin, 6 & $922.9 \pm 0.025$ & Mixed/reversible & $31.0 \pm 0.003$ & Competitive/reversible \\
Phenelzine & $146.0 \pm 0.009$ & Mixed/irreversible & $110.0 \pm 0.005$ & Mixed/irreversible \\
\hline
\end{tabular}

${ }^{*}$ Values are mean \pm SD of triplicate experiments.

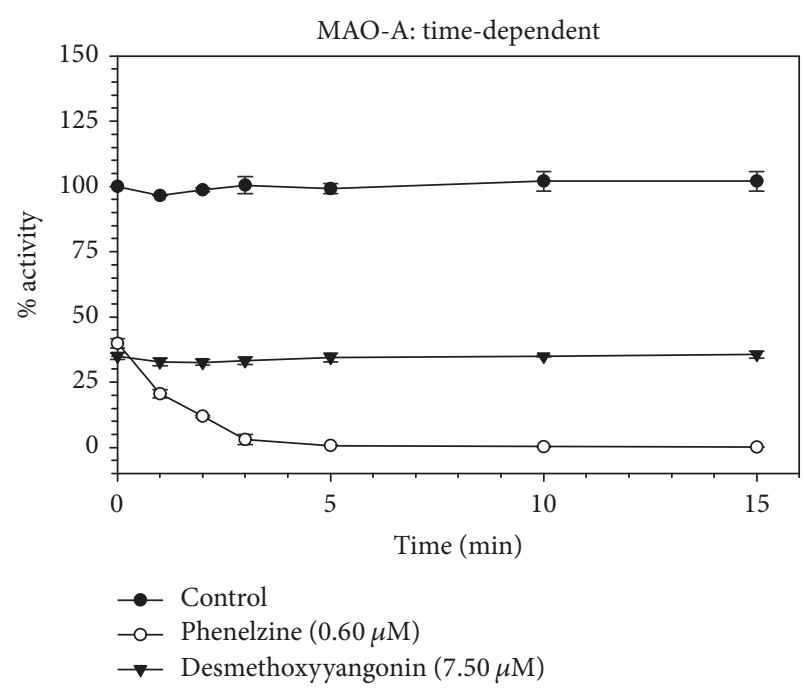

(a)

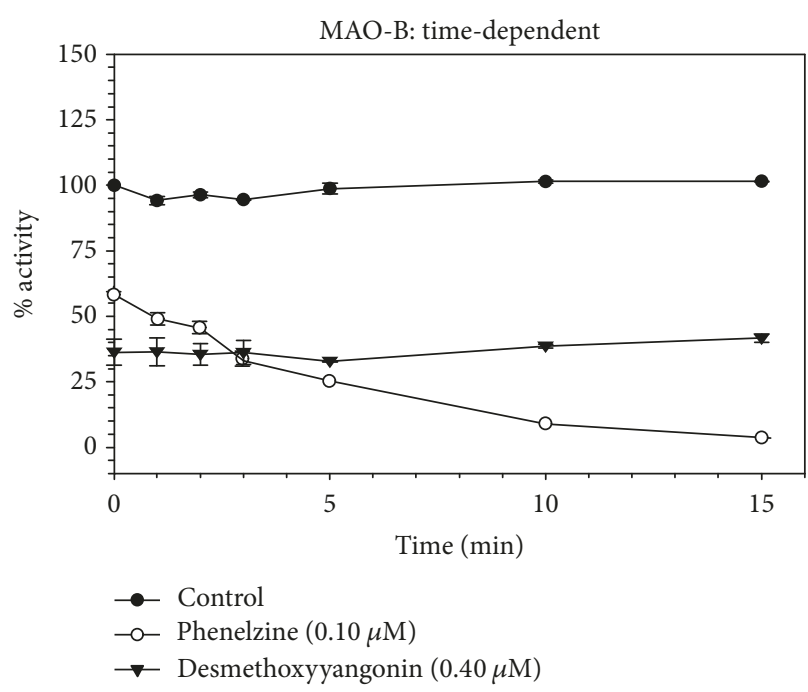

(b)

Figure 5: (a) Time-dependent inhibition of recombinant human MAO-A by phenelzine $(0.600 \mu \mathrm{M})$ and desmethoxyyangonin 6 (7.50 $\mu \mathrm{M})$. Each point represents mean \pm SD of triplicate values. (b) Time-dependent inhibition of recombinant human MAO-B by phenelzine $(0.100 \mu \mathrm{M})$ and desmethoxyyangonin $6(0.400 \mu \mathrm{M})$. Each point represents mean \pm SD of triplicate values.

concentration of desmethoxyyangonin 6 for 20 minutes at $37^{\circ} \mathrm{C}$ to allow binding of inhibitor with the enzyme and formation of enzyme-inhibitor complex. The mixtures of enzyme-inhibitor complex were dialyzed overnight at $4^{\circ} \mathrm{C}$ against $25 \mathrm{mM} \mathrm{KHPO}_{4}$ (pH-7.4) buffer. The enzyme activities were examined before and after dialysis. Through overnight dialysis, the recombinant human MAO-A enzyme lost about $10-15 \%$ of activity. Incubation of MAO-A with 20.0 and $100 \mu \mathrm{M}$ concentrations of desmethoxyyangonin 6 inhibited more than $65 \%$ of the enzyme activity (Figure 6). After the dialysis, more than $90 \%$ catalytic activity of MAO-A was recovered from enzyme-desmethoxyyangonin 6 incubation mixtures. Similarly, MAO-B lost about $10-15 \%$ of the enzyme activity during overnight dialysis. Incubation of desmethoxyyangonin $6(1.50$ and $20.0 \mu \mathrm{M})$ with MAOB caused more than $90 \%$ inhibition of enzyme activity, which was fully recovered after dialysis (Figure 6). These observations suggest that the inhibition of MAO-A and MAO-B by desmethoxyyangonin 6 was reversible due to dissociable nature of their enzyme-inhibitor complexes.

3.4. Molecular Modeling-Based Analysis of Interaction of Desmethoxyyangonin 6 with MAO-A and MAO-B. Selective inhibition of MAO-B compared to MAO-A by desmethoxyyangonin 6 led us to the investigations on interactions of
TABLE 3: Docking scores and MM/GBSA binding energies of preferred binding poses of desmethoxyyangonin 6 in MAO-A and MAO-B.

\begin{tabular}{lcc}
\hline Methods & MAO-A & MAO-B $^{\mathrm{b}}$ \\
\hline DSXP $^{\mathrm{c}}$ & -3.89 & -7.98 \\
MM/GBSA $^{\mathrm{d}}$ & -35.10 & -62.95 \\
\hline
\end{tabular}

${ }^{\mathrm{a}}$ Human monoamine oxidase-A (pdb id: 2Z5X). ${ }^{\mathrm{b}}$ Human monoamine oxidase-B (pdb id: 1OJ9). ${ }^{\mathrm{c}}$ Docking scores obtained by using extra precision module $(\mathrm{Kcal} / \mathrm{mol}) .{ }^{\mathrm{d}}$ Binding free energy that does not include contributions from receptor or ligand strain $(\mathrm{Kcal} / \mathrm{mol})$.

compound 6 with the human MAO-A and MAO-B employing computational molecular modeling algorithms. The preferred binding poses of desmethoxyyangonin 6 in MAO$\mathrm{A}$ and $\mathrm{MAO}-\mathrm{B}$ are shown in Figure 7, and their docking scores and MM/GBSA binding energies are listed in Table 3. The docking scores for the favored complexes with MAO$\mathrm{A}$ and $\mathrm{MAO}-\mathrm{B}$ are -3.89 and $-7.98 \mathrm{kcal} / \mathrm{mol}$, respectively. These scores confirm better binding of desmethoxyyangonin 6 to MAO-B than to MAO-A and support the experimental observations on selective inhibition of MAO-B compared to MAO-A, with desmethoxyyangonin 6. MM/GBSA binding energies were computed as -35.10 and $-62.95 \mathrm{Kcal} / \mathrm{mol}$ for the MAO-A and MAO-B complexes, respectively. These 


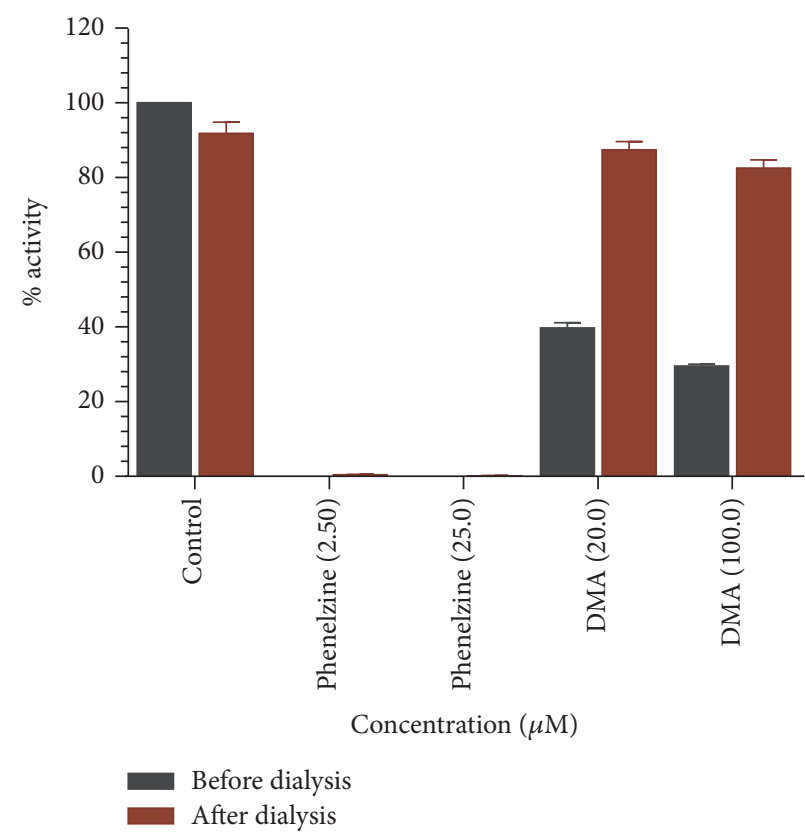

(a)

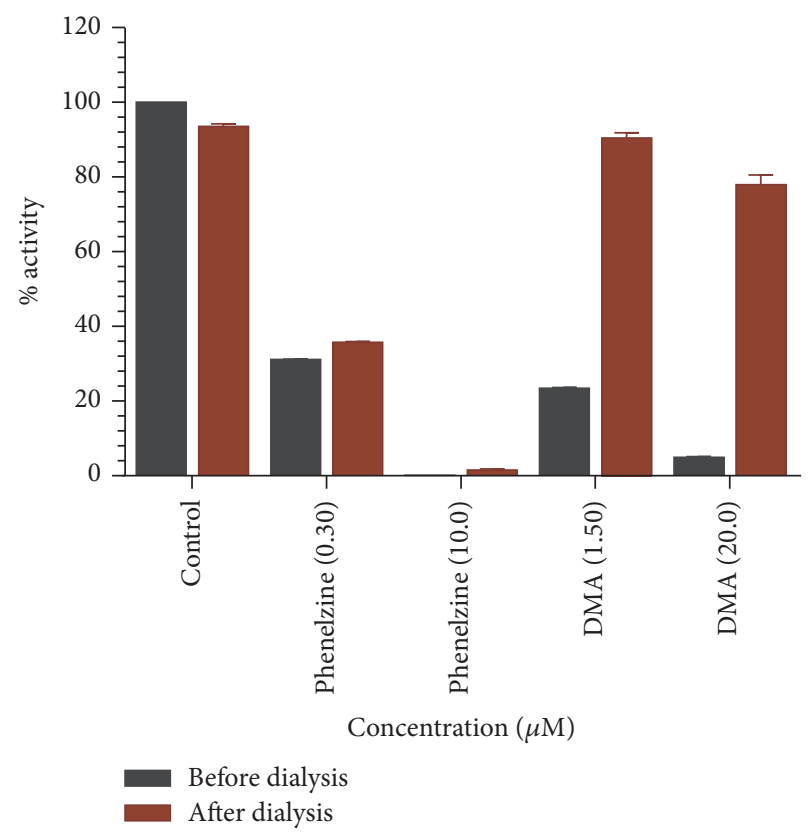

(b)

FIGURE 6: (a) Analysis of binding of phenelzine and desmethoxyyangonin 6 with recombinant human MAO-A. Recovery of catalytic activity of the enzyme after equilibrium dialysis of the enzyme-inhibitor complex. Each bar shows mean \pm SD of triplicate values. (b) Analysis of binding of phenelzine and desmethoxyyangonin $\mathbf{6}$ with recombinant human MAO-B. Recovery of catalytic activity of the enzyme after equilibrium dialysis of the enzyme-inhibitor complex. Each bar shows mean $\pm \mathrm{SD}$ of triplicate values. DMA $=$ desmethoxyyangonin.

observations are consistent with their docking scores and observed experimental $\mathrm{IC}_{50}$ and $K i$ values. Further analysis of these interactions indicates that the pyranone moiety of compound $6 \pi-\pi$ stacks with the phenol moiety of residue Y326 in MAO-B complex (Figure 7(b)), which was correspondingly replaced by residue I335 in MAO-A complex (blue-circled in Figures 7(c) and 7(d), resp.). To facilitate this $\pi-\pi$ stacking interaction, compound 6 in MAO-B stays farther away from FAD than that in MAO-A (Figures 7(e) and 7(f)). The sulfhydryl hydrogen of residue C172 in MAO$\mathrm{B}$ complex also interacts with pyran and ketone oxygens of 6, which was correspondingly replaced by residue N181 in complex MAO-A (white-circled in Figures 7(c) and 7(d), resp.). In spite of these differences, residues interacting with the pyranone moiety are very similar in both MAO$\mathrm{A}$ and MAO-B complexes. Specifically, the pyranone moiety interacts with I207, Y444, Y69, Y407, F352, Q215, and L337 in MAO-A complex and correspondingly with I198, Y435, Y60, Y398, F343, Q206, and L328 in MAO-B complex, respectively. The residues, which interact with phenyl vinyl moiety of desmethoxyyangonin $\mathbf{6}$, are quite different in MAO-A and MAO-B complexes. Specifically, in MAO-B complex residues P104, W119, and F168 contact with phenyl vinyl moiety of desmethoxyyangonin $\mathbf{6}$, whereas only one aromatic residue F208 was found to be involved in interaction with phenyl vinyl moiety in MAO-A complex (yellow-circled in Figures $7(\mathrm{c})$ and $7(\mathrm{~d})$ ). In addition, phenyl vinyl moiety was found to have contact also with residues I180, I325, L97, A111, C323, and V210 in MAO-A complex but with residues I199, I316, L164, $\mathrm{P} 102$, L167, and L171 in MAO-B complex (green-circled in
Figures $7(\mathrm{c})$ and $7(\mathrm{~d})$ ). These differences in interaction might cause rotation of phenyl vinyl moiety of approximately $180^{\circ}$ above the (pyranone) $\mathrm{C}-\mathrm{C}$ (vinyl) bond from its position in MAO-A to that in MAO-B (Figures 7(c) and 7(f)) and further imply better binding of desmethoxyyangonin 6 to MAO-B than to MAO-A.

\section{Discussion}

Many herbs remedies contain MAO inhibitors without the unpleasant side effects. Recently, Carradori et al. [33] have listed common natural sources and the chemical features responsible for inhibition of MAO-B, justifying the potential use of folk herbs and natural products for treatment of neurodegenerative diseases. Desmethoxyyangonin $\mathbf{6}$ is one of the main kava-pyrone derivatives known as kavalactones. Kavalactones are bioactive principles of the traditional beverage kava-kava, made from Piper methysticum used to treat anxiety [34]. The neurobiological activities of kavalactones primarily include modulation of gamma-aminobutyric acid type A receptors (GABA) [35]. Isolated kavalactones have shown other neurological activities potential for the treatment of neurodegenerative diseases. In fact, some potential therapeutic actions, namely, anxiety, tension, and restlessness, of standardized extracts of kava-kava roots have been attributed to kava pyrones, desmethoxyyangonin $\mathbf{6}$, and $(+/-)$-methysticin through inhibition of platelet MAO-B [36]. Similarly, kavapyrones have also been reported to show several psychotropic and neuropharmacological properties, namely, relaxation, euphoria, sleepiness, skeletal muscle 


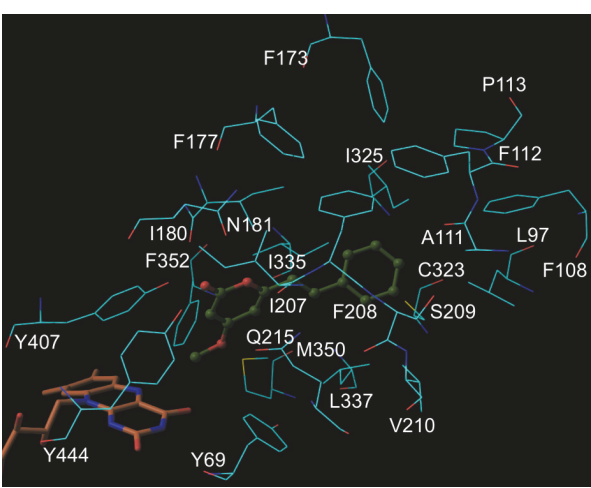

(a)

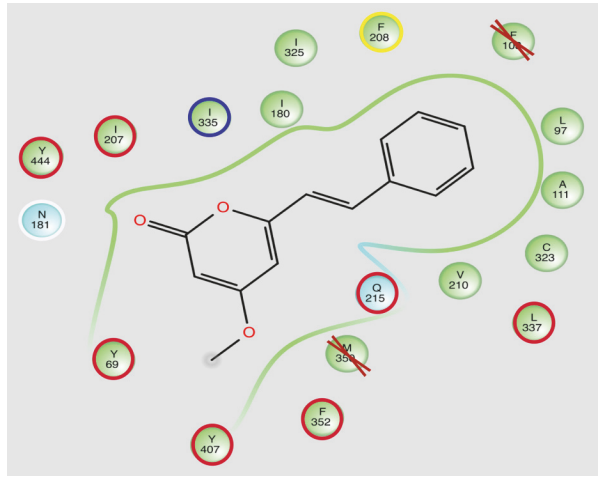

(c)

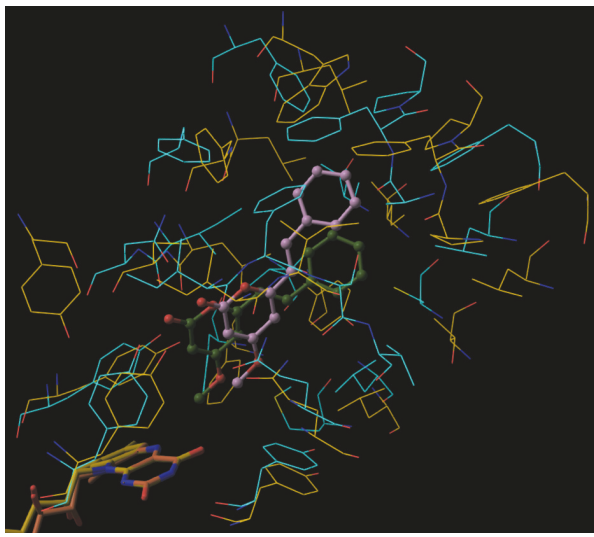

(e)

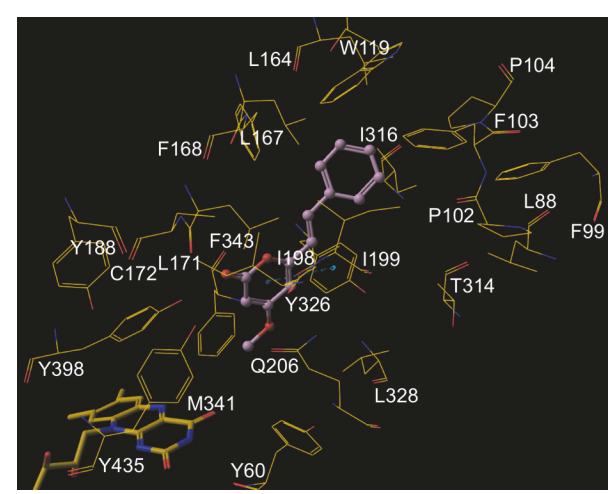

(b)

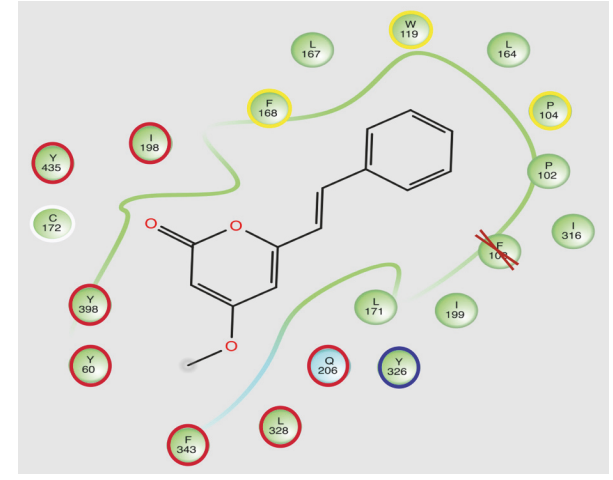

(d)

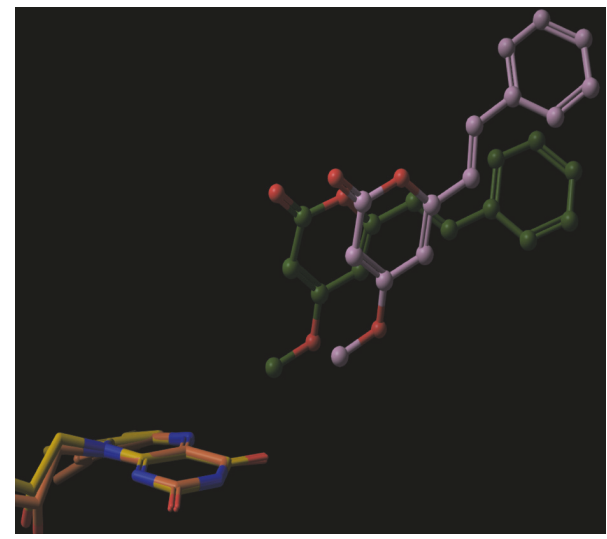

(f)

Figure 7: ( $(a, c)$ The most preferred binding poses of desmethoxyyangonin 6 in MAO-A and (b, d) for MAO-B. (e, f) The superposition of the complexes.

relaxation, anticonvulsant properties, neuroprotection, and analgesia. Treatment of rats with kava extract caused changes in their behavior and increased the levels of dopamine in nucleus accumbens [37]. Methysticin, kavain, and yangonin have been reported to induce ERK1/2 phosphorylation, while dihydro-5,6-dehydrokavain and desmethoxyyangonin have been shown to inhibit peroxide-induced P38 phosphorylation [38]. Desmethoxyyangonin 6 has been reported to prevent inflammation and hepatitis in mice through attenuation of lipopolysaccharide- (LPS-) stimulated inflammation in murine macrophages and LPS/D-galactosamine- (LPS/DGalN-) induced fulminant hepatitis in mice [15]. Moreover, kavalactones such as desmethoxyyangonin $\mathbf{6}$ have not been listed under PAINS (pan assay interference), and $\mathbf{6}$ does not contain any PAIN-like motif $[39,40]$.

The presence of pinostrobin $\mathbf{1}$ and desmethoxyyangonin 6 in $R$. alpinia further explains the potential benefits of this plant for human health and nutrition. Antiinflammatory properties and selective reversible inhibition of human MAO-B by desmethoxyyangonin $\mathbf{6}$ suggest potential 
therapeutic use of this kavalactone for treatment of neurodegenerative diseases like Parkinson's disease.

\section{Conclusion}

In this study, phytochemical analysis of dichloromethane extract of $R$. alpinia after fractionation and purification produced pure desmethoxyyangonin $\mathbf{6}$, which was further evaluated for the inhibitory effects against recombinant human MAO-A and MAO-B enzymes. Desmethoxyyangonin 6 was identified as a prominent MAO-A and MAO$\mathrm{B}$ inhibitory constituent from $R$. alpinia. The computational docking and thermodynamic analysis of MAO-A and MAO-B complexed with desmethoxyyangonin $\mathbf{6}$ support the experimental results regarding 29-fold selective inhibition of MAO-B compared to MAO-A. The presence of prominent MAO-B constituent supports the $R$. alpinia folkloric use, and desmethoxyyangonin $\mathbf{6}$ can be used as a lead compound for rational design of anti-Parkinson's disease agents.

\section{Disclosure}

The content is solely the responsibility of the authors and does not necessarily represent the official views of the NIGMS or the NIH. A portion of the results reported in this paper was presented at the 15th Annual Oxford International Conference on the Science of Botanicals (ICSB), Oxford, MS, USA, and the abstract has been published in a supplement issue of Planta Medica (Planta Med 2015; 81, -PB19) (https:// thieme-connect.com/products/ejournals/abstract/10.1055/s0035-1545174).

\section{Conflicts of Interest}

The authors declare no conflicts of interest.

\section{Acknowledgments}

This study has been supported in part by the National Institute of General Medical Sciences (NIGMS) (Grant no. P20GM104932), a component of the National Institutes of Health (NIH) and the Sustainability Strategy 2015-2016 of the Ophidism/Scorpionism Program and Serpentarium of University of Antioquia. Furthermore, this investigation was conducted in a facility constructed with support from research facilities improvement program C06RR14503 from the NIH National Center for Research Resources (NCRR). The authors are thankful to the National Center for Natural Products Research for the facilities to support this work.

\section{References}

[1] T. E. Särkinen, M. F. Newman, P. J. M. Maas et al., "Recent oceanic long-distance dispersal and divergence in the amphiAtlantic rain forest genus Renealmia L.f. (Zingiberaceae)," Molecular Phylogenetics and Evolution, vol. 44, no. 3, pp. 968980, 2007.

[2] A. Antonelli and I. Sanmartín, "Why are there so many plant species in the Neotropics?" Taxon, vol. 60, no. 2, pp. 403-414, 2011.
[3] D. A. Focho, W. T. Ndam, and B. A. Fonge, "Medicinal plants of Aguambu-Bamumbu in the Lebialem highlands, Southwest Province of Cameroon," African Journal of Pharmacy and Pharmacology, vol. 3, no. 1, pp. 1-13, 2009.

[4] M. H. K. Tchuendem, J. A. Mbah, A. Tsopmo et al., "Antiplasmodial sesquiterpenoids from the African Renealmia cincinnata," Phytochemistry, vol. 52, no. 6, pp. 1095-1099, 1999.

[5] R. R. B. Negrelle, "Renealmia 1..f.: Botanical, pharmacological and agronomical aspects," Revista Brasileira de Plantas Medicinais, vol. 17, no. 2, pp. 274-290, 2015.

[6] B. J. Cabanillas, A.-C. Le Lamer, D. Olagnier et al., "Leishmanicidal compounds and potent PPAR $\gamma$ activators from Renealmia thyrsoidea (Ruiz \& Pav.) Poepp. \& Endl," Journal of Ethnopharmacology, vol. 157, pp. 149-155, 2014.

[7] W. Milliken and B. Albert, "The use of medicinal plants by the Yanomami Indians of Brazil,” Economic Botany, vol. 50, no. 1, pp. 10-25, 1996.

[8] M. J. Macía, "Renealmia alpinia (Rottb.) Maas (Zingiberaceae): an edible plant from Sierra Norte de Puebla (México)," Anales del Jardín Botánico de Madrid, vol. 60, no. 1, pp. 183-187, 2002.

[9] C. Lans, T. Harper, K. Georges, and E. Bridgewater, "Medicinal and ethnoveterinary remedies of hunters in Trinidad," $B M C$ Complementary and Alternative Medicine, vol. 1, article 10, 17 pages, 2001.

[10] R. Otero, R. Fonnegra, S. L. Jiménez et al., "Snakebites and ethnobotany in the northwest region of Colombia. Part I: traditional use of plants," Journal of Ethnopharmacology, vol. 71, no. 3, pp. 493-504, 2000.

[11] A. Camilo Patiño, D. María Benjumea, and J. Andrés Pereañez, "Inhibition of venom serine proteinase and metalloproteinase activities by Renealmia alpinia (Zingiberaceae) extracts: Comparison of wild and in vitro propagated plants," Journal of Ethnopharmacology, vol. 149, no. 2, pp. 590-596, 2013.

[12] I. Gómez-Betancur, J. A. Pereañez, A. C. Patiño, and D. Benjumea, "Inhibitory effect of pinostrobin from Renealmia alpinia, on the enzymatic and biological activities of a PLA2," International Journal of Biological Macromolecules, vol. 89, pp. 35-42, 2016.

[13] I. Gómez-Betancur, D. Benjumea, A. Patiño, N. Jiménez, and E. Osorio, "Inhibition of the toxic effects of Bothrops asper venom by pinostrobin, a flavanone isolated from Renealmia alpinia (Rottb.) MAAS," Journal of Ethnopharmacology, vol. 155, no. 3, pp. 1609-1615, 2014.

[14] I. Gómez-Betancur, N. Cortés, D. Benjumea, E. Osorio, F. León, and S. J. Cutler, "Antinociceptive activity of extracts and secondary metabolites from wild growing and micropropagated plants of Renealmia alpinia," Journal of Ethnopharmacology, vol. 165, pp. 191-197, 2015.

[15] T.-W. Chou, J.-H. Feng, C.-C. Huang et al., "A plant kavalactone desmethoxyyangonin prevents inflammation and fulminant hepatitis in mice," PLoS ONE, vol. 8, no. 10, Article ID e77626, 2013.

[16] N. Gökhan-Kelekçi, S. Yabanoğlu, E. Küpeli et al., "A new therapeutic approach in Alzheimer disease: Some novel pyrazole derivatives as dual MAO-B inhibitors and antiinflammatory analgesics," Bioorganic and Medicinal Chemistry, vol. 15, no. 17, pp. 5775-5786, 2007.

[17] J. G. Villarinho, K. D. V. Pinheiro, F. D. V. Pinheiro et al., "The antinociceptive effect of reversible monoamine oxidaseA inhibitors in a mouse neuropathic pain model," Progress in Neuro-Psychopharmacology and Biological Psychiatry, vol. 44, pp. 136-142, 2013. 
[18] W. Liu, A. Rabinovich, Y. Nash et al., "Anti-inflammatory and protective effects of MT-031, a novel multitarget MAO-A and $\mathrm{AChE} / \mathrm{BuChE}$ inhibitor in scopolamine mouse model and inflammatory cells," Neuropharmacology, vol. 113, pp. 445-456, 2017.

[19] N. D. Chaurasiya, V. Gogineni, K. M. Elokely et al., "Isolation of acacetin from Calea urticifolia with inhibitory properties against human monoamine oxidase-A and -B," Journal of Natural Products, vol. 79, no. 10, pp. 2538-2544, 2016.

[20] S. Parikh, S. Hanscom, P. Gagne, C. Crespi, and C. Patten, "A Fluorescent-based, high-throughput assay for detecting inhibitors of human," Tech. Rep. S02T081R2, BD Biosciences Discovery Labware, Woburn, Mass, USA, 2002.

[21] S.-Y. Son, J. Ma, Y. Kondou, M. Yoshimura, E. Yamashita, and T. Tsukihara, "Structure of human monoamine oxidase A at 2.2- $\AA$ resolution: The control of opening the entry for substrates/inhibitors," Proceedings of the National Academy of Sciences of the United States of America, vol. 105, no. 15, pp. 5739$5744,2008$.

[22] C. Binda, M. Li, F. Hubálek, N. Restelli, D. E. Edmondson, and A. Mattevi, "Insights into the mode of inhibition of human mitochondrial monoamine oxidase B from high-resolution crystal structures," Proceedings of the National Academy of Sciences of the United States of America, vol. 100, no. 17, pp. 97509755, 2003.

[23] G. Madhavi Sastry, M. Adzhigirey, T. Day, R. Annabhimoju, and W. Sherman, "Protein and ligand preparation: parameters, protocols, and influence on virtual screening enrichments," Journal of Computer-Aided Molecular Design, vol. 27, no. 3, pp. 221-234, 2013.

[24] "Schrödinger Suite 2015-3 Protein Preparation Wizard; Epik version 3.3, Schrödinger," Impact version 6.8, Schrödinger, LLC, New York, NY, USA, 2015; Prime version 4.1, Schrödinger, LLC, New York, NY, USA, 2015.

[25] J. L. Banks, H. S. Beard, Y. Cao et al., "Integrated Modeling Program, Applied Chemical Theory (IMPACT)," Journal of Computational Chemistry, vol. 26, no. 16, pp. 1752-1780, 2005.

[26] W. L. Jorgensen and J. Tirado-Rives, "The OPLS [optimized potentials for liquid simulations] potential functions for proteins, energy minimizations for crystals of cyclic peptides and crambin," Journal of the American Chemical Society, vol. 110, no. 6, pp. 1657-1666, 1988.

[27] G. A. Kaminski, R. A. Friesner, J. Tirado-Rives, and W. L. Jorgensen, "Evaluation and reparametrization of the OPLSAA force field for proteins via comparison with accurate quantum chemical calculations on peptides," Journal of Physical Chemistry B, vol. 105, no. 28, pp. 6474-6487, 2001.

[28] D. Shivakumar, J. Williams, Y. Wu, W. Damm, J. Shelley, and W. Sherman, "Prediction of absolute solvation free energies using molecular dynamics free energy perturbation and the opls force field," Journal of Chemical Theory and Computation, vol. 6, no. 5, pp. 1509-1519, 2010.

[29] Glide, version 6.8, Schrödinger, LLC, New York, NY, USA, 2015.

[30] LigPrep, version 3.5, Schrödinger, LLC, New York, NY, USA, 2015.

[31] C. Mulakala and V. N. Viswanadhan, "Could MM-GBSA be accurate enough for calculation of absolute protein/ligand binding free energies?" Journal of Molecular Graphics and Modelling, vol. 46, pp. 41-51, 2013.

[32] Prime, Schrödinger, LLC, New York, NY, USA, 2014.
[33] S. Carradori, M. D’Ascenzio, P. Chimenti, D. Secci, and A. Bolasco, "Selective MAO-B inhibitors: A lesson from natural products," Molecular Diversity, vol. 18, no. 1, pp. 219-243, 2014.

[34] A. R. Bilia, S. Gallori, and F. F. Vincieri, "Kava-kava and anxiety: Growing knowledge about the efficacy and safety," Life Sciences, vol. 70, no. 22, pp. 2581-2597, 2002.

[35] H. C. Chua, E. T. H. Christensen, K. Hoestgaard-Jensen et al., "Kavain, the major constituent of the anxiolytic kava extract, potentiates gabaa receptors: Functional characteristics and molecular mechanism," PLoS ONE, vol. 11, no. 6, Article ID e0157700, 2016.

[36] R. Uebelhack, L. Franke, and H.-J. Schewe, "Inhibition of platelet MAO-B by kava pyrone-enriched extract from Piper methysticum forster (kava-kava)," Pharmacopsychiatry, vol. 31, no. 5, pp. 187-192, 1998.

[37] S. Sällström Baum, R. Hill, and H. Rommelspacher, "Effect of kava extract and individual kavapyrones on neurotransmitter levels in the nucleus accumbens of rats," Progress in NeuroPsychopharmacology and Biological Psychiatry, vol. 22, no. 7, pp. 1105-1120, 1998.

[38] Y.-M. Tzeng and M.-J. Lee, "Neuroprotective properties of kavalactones," Neural Regeneration Research, vol. 10, no. 6, pp. 875-877, 2015.

[39] J. Baell and M. A. Walters, "Chemistry: chemical con artists foil drug discovery," Nature, vol. 513, no. 7519, pp. 481-483, 2014.

[40] J. B. Baell, "Feeling nature's pains: natural products, natural product drugs, and pan assay interference compounds (PAINS)," Journal of Natural Products, vol. 79, no. 3, pp. 616628, 2016. 


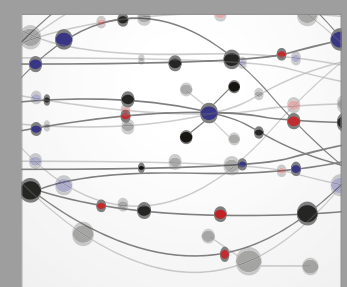

The Scientific World Journal
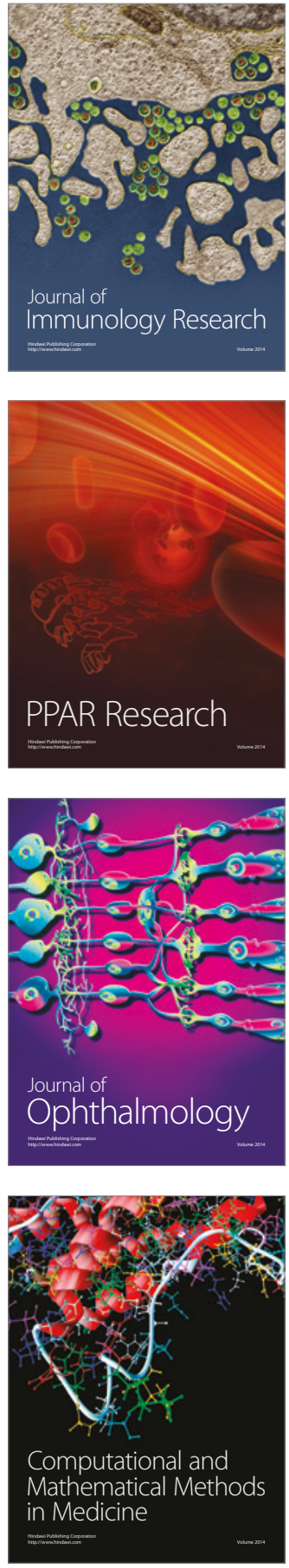

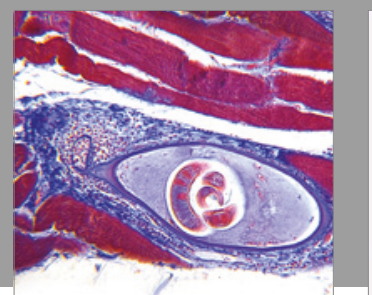

Gastroenterology Research and Practice
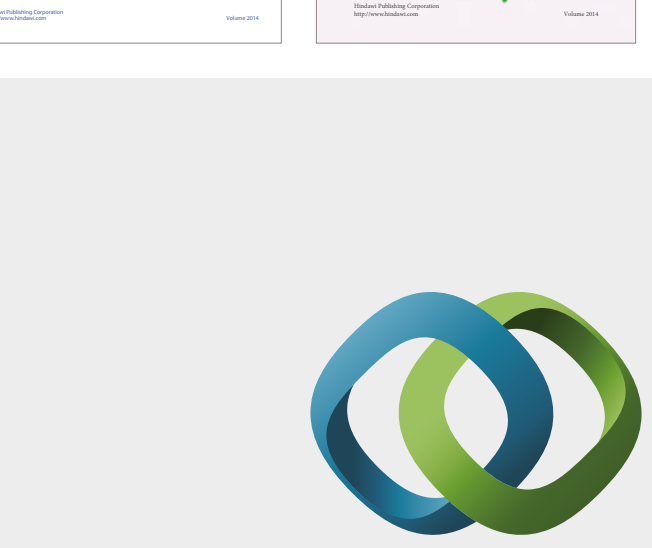

\section{Hindawi}

Submit your manuscripts at

https://www.hindawi.com
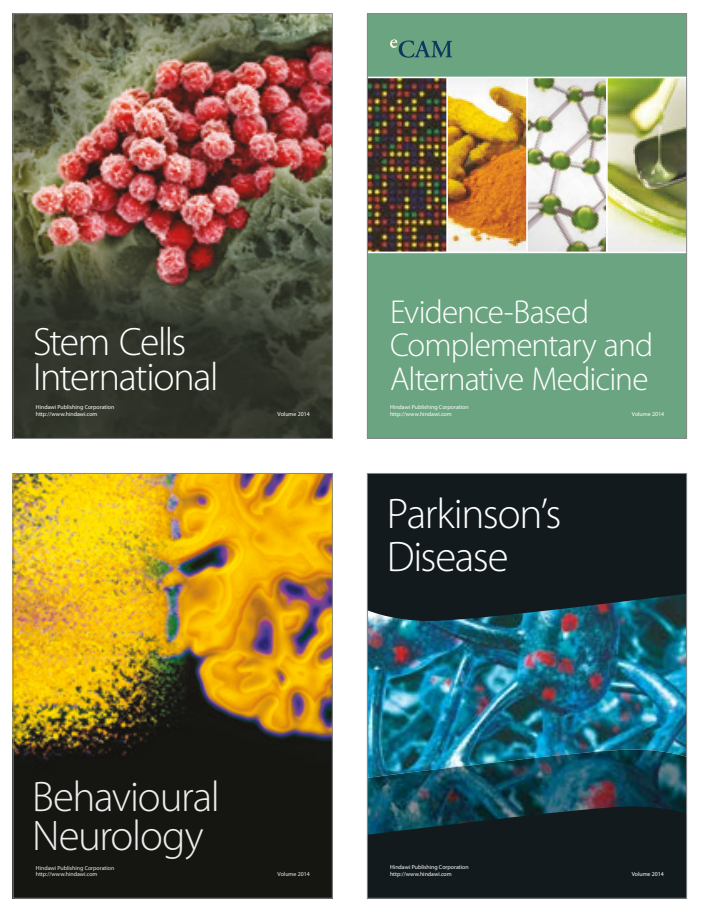
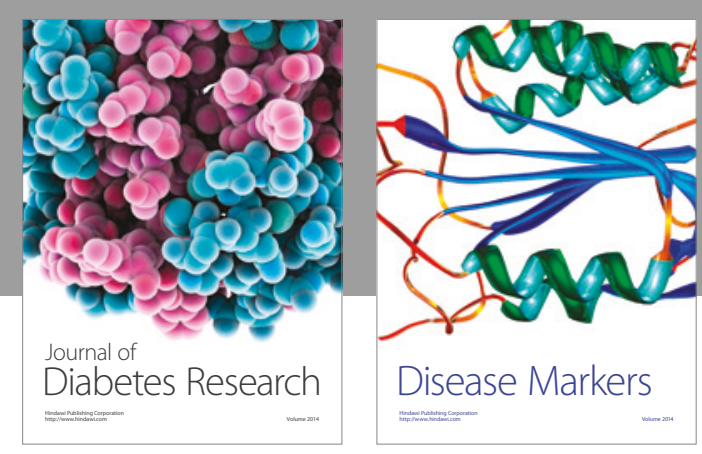

Disease Markers
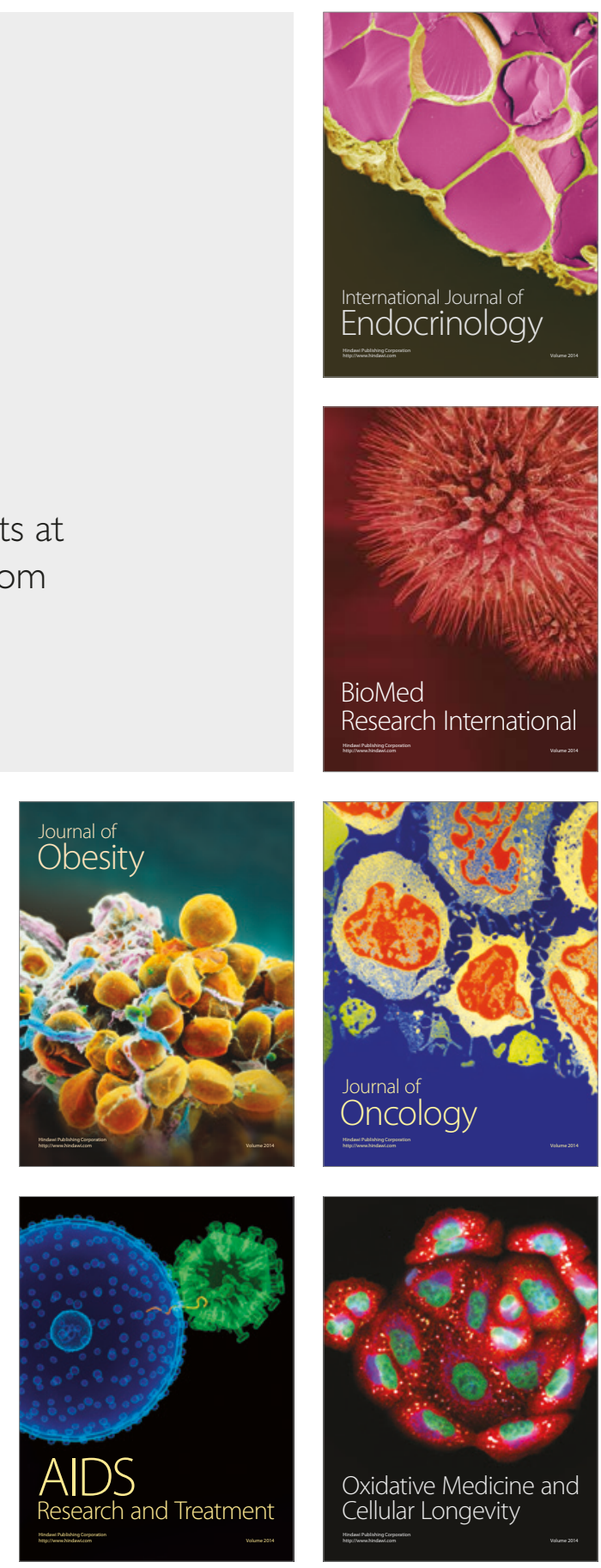